\title{
Evidence for biological shaping of hair ice
}

\author{
D. Hofmann ${ }^{1}$, G. Preuss ${ }^{2}$, and C. Mätzler ${ }^{3}$ \\ ${ }^{1}$ IBG-3: Agrosphere, Institute of Bio- and Geosciences, Forschungszentrum Jülich, Jülich, Germany \\ ${ }^{2}$ Birkenweg 7, 57555 Brachbach, Germany \\ ${ }^{3}$ Institute of Applied Physics, University of Bern, Bern, Switzerland
}

Correspondence to: D. Hofmann (d.hofmann@fz-juelich.de)

Received: 07 January 2015 - Published in Biogeosciences Discuss.: 02 April 2015

Revised: 11 June 2015 - Accepted: 15 June 2015 - Published: 22 July 2015

\begin{abstract}
An unusual ice type, called hair ice, grows on the surface of dead wood of broad-leaf trees at temperatures slightly below $0{ }^{\circ} \mathrm{C}$. We describe this phenomenon and present physical, chemical, and biological investigations to gain insight in the properties and processes related to hair ice. Tests revealed that the biological activity of a winter-active fungus is required in the wood for enabling the growth of hair ice. We confirmed the fungus hypothesis originally suggested by Wegener (1918) by reproducing hair ice on wood samples. Treatment by heat and fungicide suppresses the formation of hair ice. Fruiting bodies of Asco- and Basidiomycota are identified on hair-ice-carrying wood. One species, Exidiopsis effusa (Ee), was present on all investigated samples.

Both hair-ice-producing wood samples and those with killed fungus show essentially the same temperature variation, indicating that the heat produced by fungal metabolism is very small, that the freezing rate is not influenced by the fungus activity, and that ice segregation is the common mechanism of ice growth on the wood surface. The fungus plays the role of shaping the ice hairs and preventing them from recrystallisation. Melted hair ice indicates the presence of organic matter. Chemical analyses show a complex mixture of several thousand $\mathrm{CHO}(\mathrm{N}, \mathrm{S})$ compounds similar to fulvic acids in dissolved organic matter (DOM). The evaluation reveals decomposed lignin as being the main constituent. Further work is needed to clarify its role in hair-ice growth and to identify the recrystallisation inhibitor.
\end{abstract}

\section{Introduction}

\subsection{Characteristics of hair ice}

One of the most exciting types of ice takes the shape of fine hairs (diameter near $0.02 \mathrm{~mm}$, length up to $20 \mathrm{~cm}$ ). It can be observed in forests, on dead wood, usually on the ground and sometimes on trees that are still standing (Fig. 1). This so-called hair ice or ice wool grows on the surface of the unfrozen wood body of certain moist and rotten branches of broad-leaf trees. The hairs are smooth, often with a silky shine. They are found in bunches of beautiful structures such as curls and waves, sometimes with clear parting or zoning, but without ramification. Although individual hairs are mostly separate, they follow a macroscopic order, often with surprising regularity. The hair base is rooted at bark-free positions or where the bark is loose, but never on the bark. The outer end is either free or in contact with an ice crust or with surrounding material, such as bark or leaves. Sometimes hairs loop back to the branch. Bands of parallel hairs can sinter along contacting lines without losing the original shape until melt onset. In cold, dry air, however, hair ice sublimates within a short time. Therefore it can be observed under calm, humid conditions only, at air temperatures slightly below $0{ }^{\circ} \mathrm{C}$. We observed branches that produced hair ice repeatedly over more than 2 years. During this time, the dry density decreased to about $0.3 \mathrm{~g} \mathrm{~cm}^{-3}$ while the wood was brightening as a consequence of white rot.

Time-lapse videos of hair-ice growth support visual observations, in that the growth is controlled and synchronised over macroscopic parts of the wood. The hair curvature results from lateral gradients in the growth velocity. The primary direction is radial, the hairs being in the prolongation 


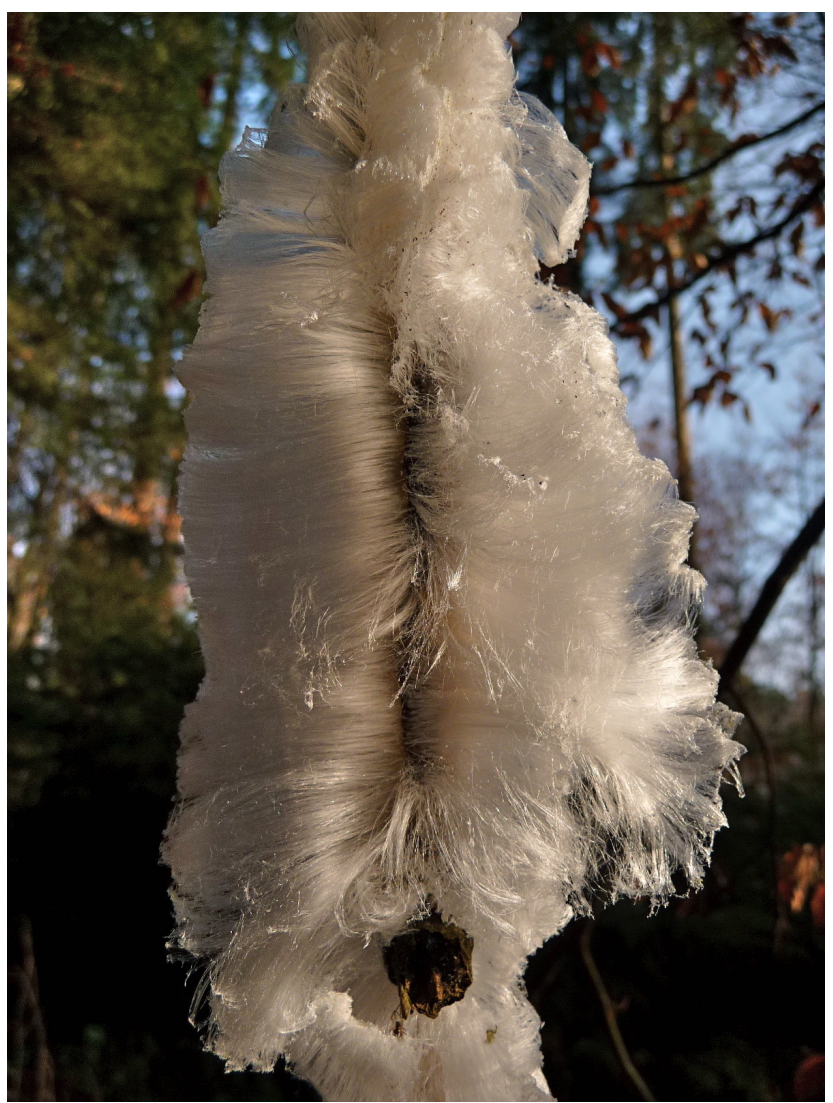

Figure 1. Hair ice on a stem of dead beechwood (26 December 2009, Moosseedorf), hair length up to $10 \mathrm{~cm}$.

of wood rays (Fig. 2). Indeed, our observations indicate that the hairs are rooted at the mouths of these rays (Wagner and Mätzler, 2009). Furthermore, the hair-ice thickness (Fig. 3) corresponds to the diameter of the cells (Figs. 8 and 9 in Sect. 2) forming the channels in the wood rays (Schweingruber, 1990).

The fine hairs can keep their shape over a long time - many hours or even days. This is surprising because recrystallisation of small ice crystals to larger ones is a fast process, especially at temperatures close to melting point. The observed stability is an indication that hair ice is doped with a recrystallisation inhibitor. Examples are antifreeze proteins (AFP), also called ice-binding proteins (IBP); see Griffith and Yaish (2004).

When the air temperature exceeds $0{ }^{\circ} \mathrm{C}$, hair ice starts to melt. Hairs fixed at both ends are transformed to a type of micro-string, covered by small water droplets (Fig. 4) before they decay. Hairs with free ends have been observed to collapse in length. The melted liquid is clear water with a slightly brownish colour, indicating the content of organic material.

We received many reports on the observation of hair ice, mainly at latitudes between 45 and $55^{\circ} \mathrm{N}$ from Canada,

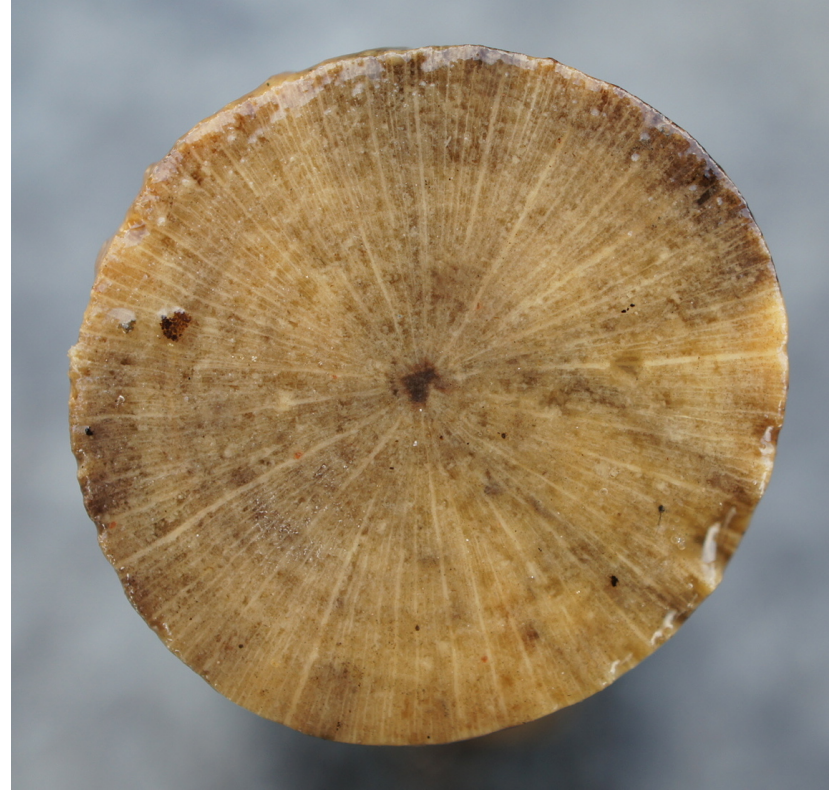

Figure 2. Cross section of a hair-ice-producing beech branch $(\varnothing 22 \mathrm{~mm})$ with radial wood rays.

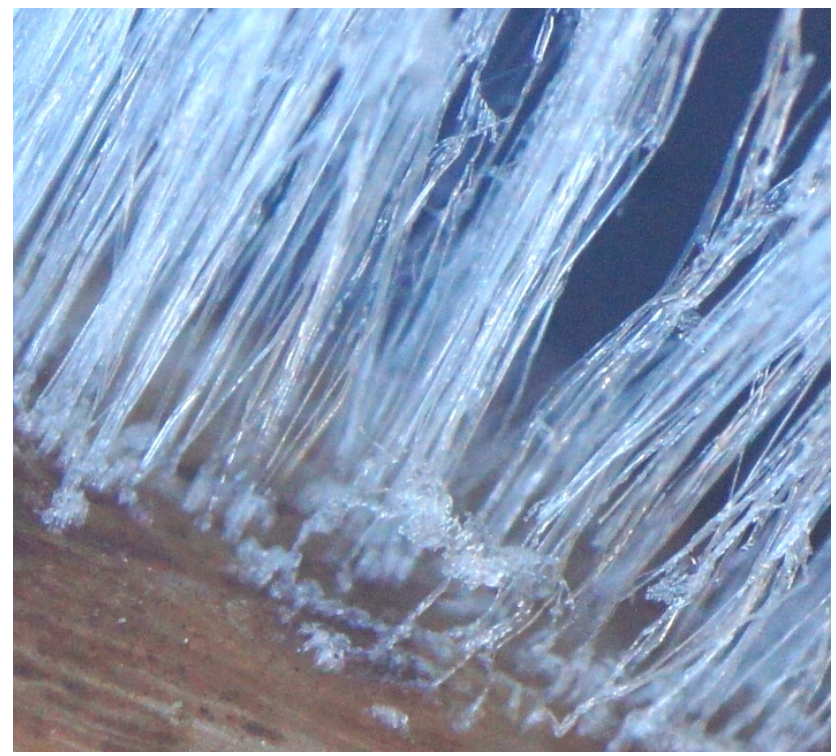

Figure 3. Enlargement of hair ice on beechwood, image width $3.2 \mathrm{~mm}$.

France, Germany, India, Ireland, Netherlands, Russia, Scotland, Slovenia, Sweden, Switzerland, USA, and Wales.

\subsection{References to earlier work and the fungus hypothesis}

Although the literature on hair ice is not abundant, it reaches back about one century. Wegener (1918), the founder of the theory on continental drifts, published the most relevant pa- 


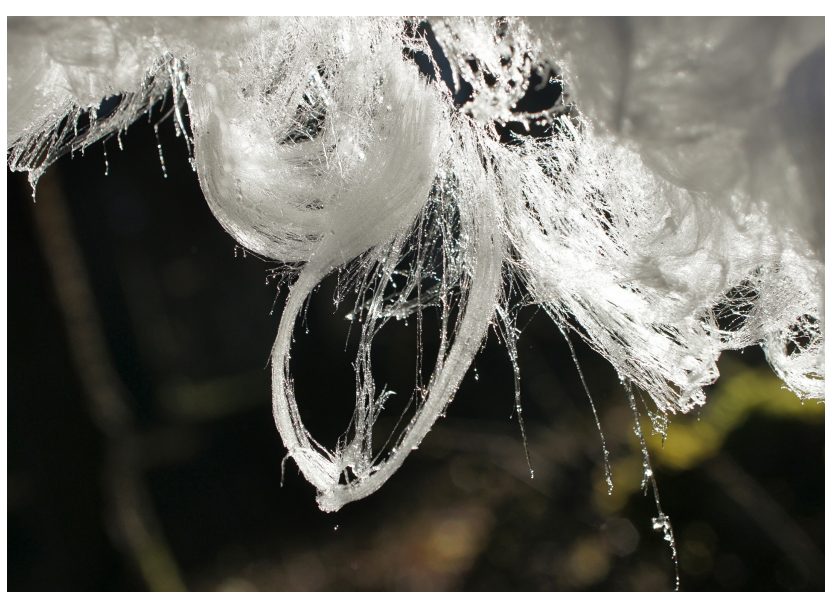

Figure 4. Melting hair ice, showing tiny droplets on hardly visible strings.

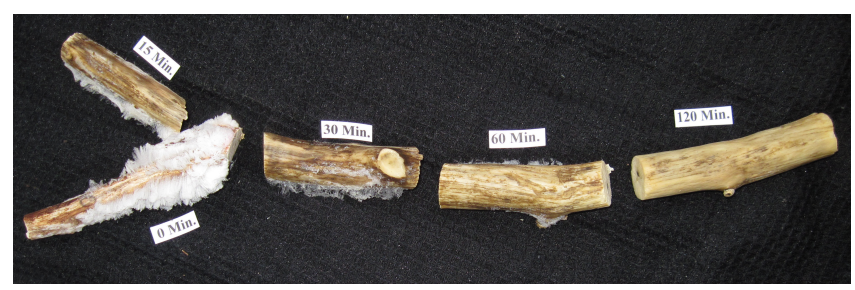

Figure 5. Reduction and suppression of hair-ice growth after fungicide treatment; durations from 0 to $120 \mathrm{~min}$ are indicated.

per of earlier work. He observed hair ice in winter 1916/1917 in the Vosges Mountains, and in February 1918 in northern Germany at Rheinsberg in der Mark. He was able to grow hair ice again on the branches that he found. Wegener assumed a relationship between the formation of hair ice and the mycelium visible on the branch surface. His consultant, Arthur Meyer, confirmed that these branches contained fungus mycelia. He assumed a type of Ascomycota; however, he was unable to determine the species. Mühleisen and Lämmle (1975) described the reproduction of hair ice on rotten wood of broad-leaf trees in a climate chamber. They assumed that some type of osmotic pressure is acting. Lenggenhager (1986) observed hair ice in areas near Bern, Switzerland from 1979 to 1985 . Being aware of these observations, Wagner (2005) supposed the involvement of a fungus activity without the knowledge of Wegener's work. Wagner found that the presence of fungus mycelia in the wood body of hair-ice-producing branches is manifested in the microscopic and macroscopic view. Fruiting bodies of fungi were observed as shown by Wagner and Mätzler (2009). They developed a method to repeatedly grow hair ice on a covered balcony during nights with freezing conditions. Their more specific hypothesis, that the metabolism of these fungi is a prerequisite for the formation of hair ice, was supported by their tests. A further hypothesis was the assumption that gas pressure, caused by fungal metabolism, ejects water through wood rays to the wood surface. Furthermore, they concluded that hair ice is formed from water stored in the wood. Dash et al. (2006) considered hair ice as a frost-heave phenomenon associated with ice segregation. In the present work we recognised signatures of this effect during hair-ice growth.

\subsection{Hair ice and ice segregation}

Hair ice grows on porous substrates containing liquid water. We call this ice type a "basicryogen", in order to distinguish it from ice that grows from atmospheric water. Different basicryogens grow on different substrates and with different ingredients. The co-existence of liquid water, ice, and the porous substrate at the ice front are common to all basicryogens. This general phenomenon is called ice segregation. The thermodynamic phenomenon of frost heave (Vignes and Dijkema, 1974; Dash, 1989; Ozawa, 1997; Dash et al., 2006) is a common driver for these ice types.

Hair ice grows on the wood surface while a connected network of water inside the wood remains in the liquid state. Due to molecular interactions at the large specific interface area between wood cells and the water, the melting point inside the wood is reduced to below $0{ }^{\circ} \mathrm{C}$ (the melting point of bulk water), which is known as premelting (Rempel et al., 2004; Dash et al., 2006). The reduction increases with increasing specific surface, i.e. with decreasing size of capillaries and pores of the wood. The depression can keep the water unfrozen inside the pores while ice is growing outside. The freezing front remains at the wood surface during ice growth. In this way, the ice is segregated from the reservoir of liquid water.

How can we understand this process? The large dipole moment of the water molecule causes charges on the surface of liquid water and ice. Energy is needed to set up the associated electric field. Surface energy can be reduced if a liquidwater film remains between the wood and the ice surface due to the flexibility of the liquid to neutralise the local charges. Under freezing conditions, suction forces are set up, caused by the interface energy of the wood-water-ice sandwich, to attract liquid water from the pores of the wood toward the freezing front. In this way the liquid-water film is maintained. Frost-heave processes in fine-grained soil also act in this way (Ozawa, 1997; Dash et al., 1995, 2006). Although the theory of ice segregation is still incomplete (Dash et al., 2006), empirical insight in the behaviour was found by experimental studies. Ozawa and Kinosita (1989) investigated ice growing on the surface of a microporous filter. The thin liquid film, separating the ice from the filter material, was confirmed. The authors observed that the growth rate of ice increases proportionally with the depression $\Delta T_{\mathrm{f}}=T_{0}-T_{\mathrm{f}}$ of the temperature $T_{\mathrm{f}}$ at the freezing front, where $T_{0}=0^{\circ} \mathrm{C}$, is the melting temperature of bulk ice $\left(\Delta T_{\mathrm{f}}\right.$ values ranging from 0.0 to $0.3^{\circ} \mathrm{C}$ ). The observations are in agreement with 
an experiment by Vignes and Dijkema (1974), who grew ice at the mouth of a capillary channel that was in contact with a reservoir of supercooled water $\left(\Delta T_{\mathrm{f}}\right.$ values ranging from 0.3 to $0.77^{\circ} \mathrm{C}$ ). With respect to growth rate and temperature range, these experiments agree with our observations of hairice growth as will be shown.

\subsection{Outline}

Advancing the understanding of the hair-ice phenomenon was the objective of this work. In Sect. 2, we will confirm that a winter-active fungus is needed for hair-ice formation. We will identify the acting fungus. In the physical analysis of Sect. 3 we will study the temperature variation of wood during ice formation. Wood samples with and without the acting fungus will be studied. The results point us to the search for a recrystallisation inhibitor produced by the fungus and thus also to the chemical analysis, detailed in Sect. 4. Final discussions and conclusions will be given in Sect. 5 .

\section{Observations and experiments related to the fungus hypothesis}

\subsection{Suppression of hair-ice growth by killing the fungus}

\subsubsection{Experiments with fungicide}

In winter 2010/2011 Gerhart Wagner refined the hair-ice experiments of Wagner and Mätzler (2009). A hair-ice-active branch was cut into five pieces (length $35 \mathrm{~cm}$, diameter $2 \mathrm{~cm}$ ) and exposed to a commercial fungicide (a Miocolor "Schimmelentferner", sodium hypochlorite, conc. 4.4\%): piece no. 0 remained untreated, no. 1 was exposed for $15 \mathrm{~min}$, no. 2 for $30 \mathrm{~min}$, no. 3 for $60 \mathrm{~min}$, and no. 4 for $120 \mathrm{~min}$. On the first evening (18 December 2010), the air temperature was close to $-10^{\circ} \mathrm{C}$. Consequently the growth of hair ice was fast, but ended after $1 \mathrm{~h}$ at a hair length of $1 \mathrm{~cm}$. The result at 21:30 LT is shown in Fig. 5. Hair ice was reduced on pieces treated with the fungicide, but complete suppression was observed for the longest treatment only.

The following morning all pieces melted at room temperature before they were exposed to the cold again. The air temperature rose from -5 to $0^{\circ} \mathrm{C}$. Two hours later, a very similar result was obtained. In the afternoon, the experiment was repeated again after wetting the branches in distilled water for a short time. The results showed the expected gradation even more clearly. All results demonstrate that the 15 min treatment causes a significant reduction in hair-ice production, and a treatment for $120 \mathrm{~min}$ stopped the production completely. During the following weeks, the same branches were repeatedly exposed to the cold. Slow recovery occurred for the fungicide pieces, in that they gradually started to grow hair ice again. The pieces with different treatment duration became more and more similar.

\subsubsection{Experiments with heat}

A hair-ice branch of about $20 \mathrm{~cm}$ in length and $2 \mathrm{~cm}$ in diameter was cut into four similar pieces on 03 January 2011. Three of them were exposed to hot $\left(90\right.$ to $\left.95^{\circ} \mathrm{C}\right)$ water for 1, 2 and $4 \mathrm{~min}$, respectively. After the frost night following, the reference was covered with dense hair ice; however, the heated pieces did not show any. The repetition with a thin branch $(1 \mathrm{~cm})$ produced the same result. Some days later, the heated pieces started to produce traces of hair ice again.

\subsubsection{Other treatments}

Treating the branches with alcohol (70\%) or with the weak fungicide, Imaverol - an imidazole, also called Enilconazole $\left(\mathrm{C}_{14} \mathrm{H}_{14} \mathrm{Cl}_{2} \mathrm{~N}_{2} \mathrm{O}\right)$, often used in veterinary medicine - did not affect hair-ice growth.

\subsubsection{Results}

Heat treatment showed the most radical hindrance to hairice growth. $1 \mathrm{~min}$ in hot water was sufficient for a complete suppression. For fungicides, the type and duration of the treatment played a role. Whereas our weak fungicide did not have any effect, complete suppression was achieved with the stronger fungicide after treatment lasting $2 \mathrm{~h}$. The results are plausible in view of the fungus hypothesis. At a temperature of at least $90^{\circ} \mathrm{C}$ the active cells of the fungus are killed rapidly. Fungicides act much more slowly. Several days or weeks after the treatments, hair-ice growth starts again, either due to the recovery of the mycelium or due to the survival of spores.

\subsection{Identification of the fungus and microscopic studies on hair-ice-producing wood}

\subsubsection{Methods}

From January to March 2012, from December 2012 to April 2013, and from November 2013 to March 2014, a total of 78 hair-ice-bearing twigs and branches were collected in the forests near Brachbach/Sieg in Germany (northern slope of "Windhahn"). Some of them were kept on a moss-covered shadowy area or temporarily on a wet towel in a closed plastic box in the garden of one of the authors (G. Preuss) to simulate forest-floor conditions. Additionally, 41 hair-ice-bearing trees, boles, and branches were observed in their natural location in the forest. Most of the species, or at least the genus of the dead branches, were identified by species-specific characteristics visible in the microscopic wood anatomy (Schoch et al., 2004, and Richter and Dallwitz, 2000). Fungi growing on the examined branches and logs were identified if necessary by microscopic characteristics with the help of Gminder (2008), Haller and Probst (1983), Jülich (1984), Krieglsteiner (2000), Laux (2010), Moser (1963), and Rothmaler (1994). Samples 
of the fruiting bodies were prepared as squash mounts and sometimes coloured by Phloxine B to stain the basidia. Handcut sections of hair-ice-bearing wood samples were prepared as wet mounts and afterwards coloured by the dye "Cotton Blue", following the instructions of Bavendamm (1936) according to the description of Riggenbach (1959). This is an approved method to make fungal hyphae visible within wood cells.

\subsubsection{Observations and results}

The type of examined hair-ice wood varied from fallen twigs, attached and fallen branches, to dead standing trees and fallen or felled boles, except for one case: a hazel tree, which was still living, bore hair ice several times on a dead part of the wood.

In the majority of cases the consistency of the dead wood was "rather hard" - indicating an initial stage of decay - but four samples had a "distinctly softened" texture, adopting the terms of Heilmann-Clausen and Christensen (2003). The integrity of the bark differed from almost intact to completely lost. If it still existed at all, the bark peeled off from the hairice-producing wood surface and often got lost during the observation period.

Hair ice was observed on ten different broad-leaf tree species belonging to five different plant families (Table 1).

Eleven different fungal fruiting bodies were identified on the wood samples - in some cases up to three species on the same piece of wood. The list is certainly not complete. One of these fungi, Exidiopsis effusa (Ee), deserves closer attention, as it colonised all our hair-ice-producing wood samples. In more than half of the samples, it was the only detectable fungus, but in most cases it was not yet visible macroscopically when hair ice occurred for the first time in late autumn. Its unspectacular fruiting body appeared some weeks later as a thin whitish coating (Fig. 6) exactly on those areas of the wood surface where hair ice had grown before (Fig. 6b, d, f) or next to the hair-ice area (Fig. 6d). In the first observation period (winter 2011/2012) the coating was present on every observed sample from February onwards; in the second and third winter, the first fruiting bodies were visible in January. The colour was sometimes slightly bluish, greyish or light-pink tinted, depending on the humidity and colour of the wood.

Under humid conditions (in nature or in a closed plastic box containing a wet towel) and at temperatures above freezing, small water droplets often appeared on the surface of the Ee fruiting body overnight (Fig. 6f). This might be a case of guttation, which is the active exudation of an aqueous solution. The phenomenon is well-known related to different vascular plants, but also related to some fungi (Knoll, 1912; Thielke, 1983). The observation of Sprecher (1959), who describes a reinforcing effect at temperatures near $+4{ }^{\circ} \mathrm{C}$ on the guttation activity of a fungus, is particularly interesting with

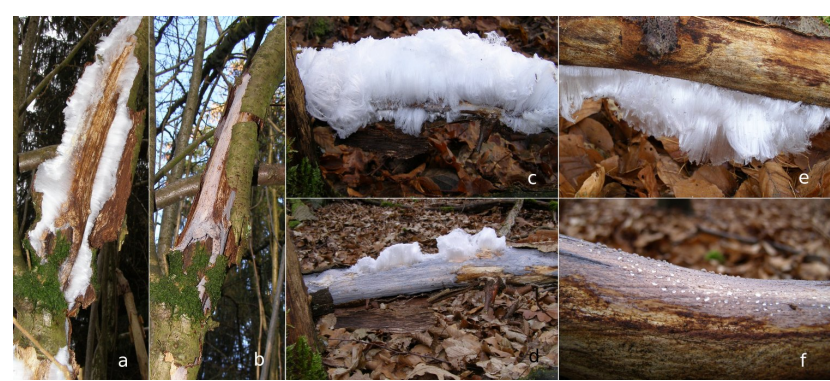

Figure 6. Three wood samples, first with hair ice, later with the fruiting body of Exidiopsis effusa (Ee): Corylus avellana $(\varnothing 3.8 \mathrm{~cm})$ on 29 January 2012 (a) and 15 March 2012 (b), Carpinus betulus $(\varnothing 3.2 \mathrm{~cm})$ on 25 January 2012 (c) and 7 March 2012 (d), Fagus sylvatica $(\varnothing 4.9 \mathrm{~cm})$ on 3 December 2013 (e) and 11 January 2014 (f, branch rotated by about $180^{\circ}$ ).

regard to the formation of hair ice. Further studies on Ee are necessary to clarify this aspect.

Cross sections of the fruiting body were 30 to $100 \mu \mathrm{m}$ thick with great variability (Fig. 7a, b, c). The body mainly consists of ovoid to pyriform basidia in a layer of thin, clamped hyphae. The basidia, too, are clamped at their base, are 4septate (Fig. 8a, c, d), longitudinally divided (Fig. 8a), about $10 \mu \mathrm{m}$ in diameter and ca. $15 \mu \mathrm{m}$ long without the sterigmata. The spores (Fig. 8b) are weakly allantoidal, $13-15 \mu \mathrm{m}$ long and $4-5 \mu \mathrm{m}$ in diameter and often contain one big oil drop in the middle. Based on these characteristics the fungus was identified as Exidiopsis effusa (Ee) with the help of the manual of Jülich (1984). The descriptions at www.mycobank.org (Robert et al., 2005) and www.mycokey.com (Petersen and Læssøe, 2003) confirm the result, while Krieglsteiner (2000) classifies the fungus as Exidiopsis grisea var. effusa.

Beneath the fruiting body, the superficial wood cells are almost filled by hyphae (Fig. 7a, b). The fungus seems to grow along the wood vessels (Fig. 9a) and intrude into the deeper wood tissue along the wood rays (Figs. 7c and 9b).

Some hair-ice wood samples found in November were examined by microscope, too. At that time of the year, there was no macroscopic sign of a fungal fruiting body on the wood surface. But when microscopic mounts were coloured by the dye "Cotton Blue", they showed, that the wood tissue was pervaded by fungal hyphae running along the wood vessels and rays (Fig. 9b). Except for the density of the hyphae, the findings looked exactly like those from the wood samples with an Ee fruiting body.

As our main result, we unravelled the mystery about the whitish covering described by Wegener (1918) and Wagner (2005) by the identification of Ee. The opinion of Wegener's consultant, A. Meyer, who did not expect the appearance of a fruiting body and thought that the determination of the species would be impossible, has been disproved. Furthermore, the result specifies the fungus hypothesis of Wagner and Mätzler (2009). 
Table 1. Hair-ice-bearing wood species, range of diameters and identified fungal species D is Dacrymyces spec., Dd is Diatrype disciforme, Dst is Diatrype stigma, E is Exidia spec., Ee is Exidiopsis effusa, Ff is Fomes fomentaria, Hf is Hypoxylon fragiforme, Hm is Hypoxyon multiforme, Sch is Schizopora paradoxa, Pc is Pycnoporus cinnabaria, and Tm is Tremella mesenterica.

\begin{tabular}{|c|c|c|c|}
\hline Fam. & Species (in brackets, number of finds) & Diameter $(\mathrm{cm})$ & Fungi \\
\hline Aceraceae & Acer pseudoplatanus (4) & $1.3-4.8$ & $\underline{\mathrm{Ee}}$ \\
\hline Adoxaceae & Sambucus nigra (3) & $1.5-2.5$ & $\underline{\mathrm{Ee}}$ \\
\hline Betulaceae & $\begin{array}{l}\text { Betula pendula }(3) \\
\text { Carpinus betulus }(15) \\
\text { Corylus avellana }(16) \\
\text { Alnus glutinosa }(14)\end{array}$ & $0.5-13.0$ & $\overline{\mathrm{D}}, \mathrm{Dd}, \mathrm{Dst}, \mathrm{E}, \underline{\mathrm{Ee}}, \mathrm{Hm}, \mathrm{Sch}$ \\
\hline Fagaceae & $\begin{array}{l}\text { Fagus sylvatica }(32) \\
\text { Quercus spec. }(12, \text { robur/petraea/bastards })\end{array}$ & $0.5-18.0$ & $\mathrm{Dd}, \underline{\mathrm{Ee}}, \mathrm{Ff}, \mathrm{Hf}, \mathrm{Sch}$ \\
\hline Rosaceae & $\begin{array}{l}\text { Prunus avium (2) } \\
\text { Sorbus aucuparia (18) }\end{array}$ & $0.6-6.0$ & $\mathrm{Dd}, \mathrm{E}, \underline{\mathrm{Ee}}, \mathrm{Pc}, \mathrm{Tm}$ \\
\hline
\end{tabular}

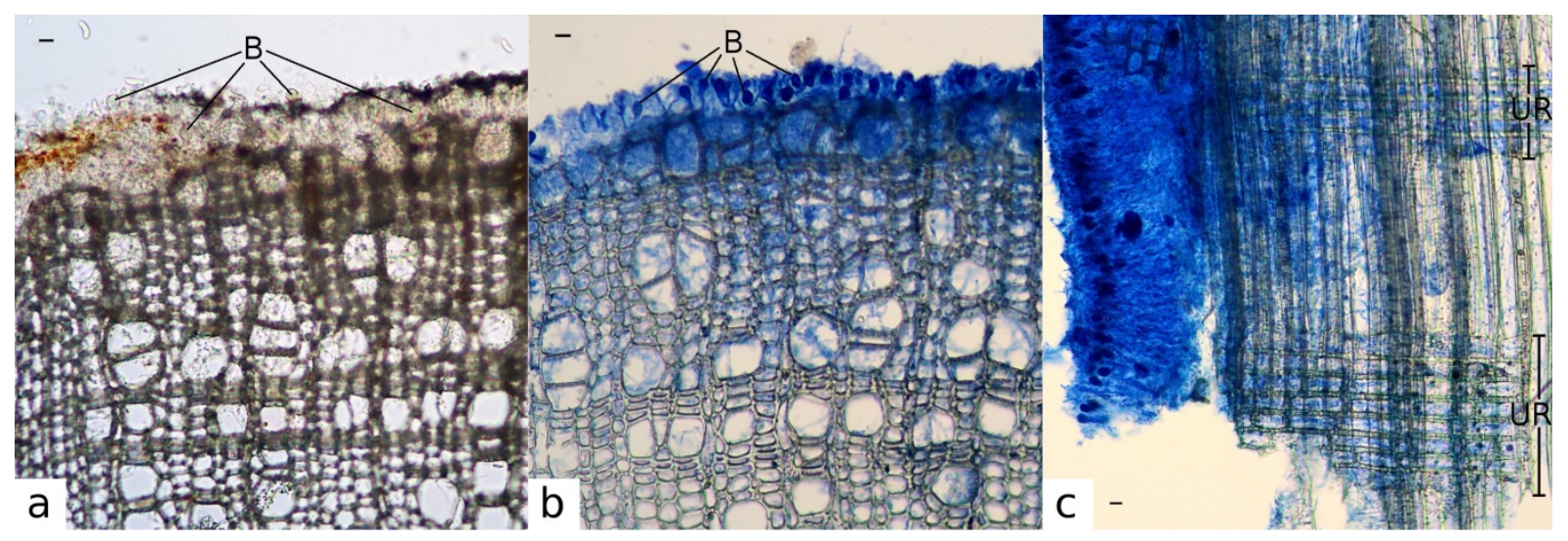

Figure 7. Microscopic views of a hair-ice wood sample (Alnus glutinosa twig, $\varnothing 9 \mathrm{~mm}$ ) with the Ee fruiting body. In images (b) and (c), the fungal hyphae and basidia were coloured by "Cotton Blue" (scale bar $10 \mu \mathrm{m}, \mathrm{B}$ are basidia, UR are uniseriate rays). Panels (a) and (b) show cross sections of an Alnus glutinosa twig with a thin Ee fruiting body. The wood vessels are shown in the cross section. (c) Radial section of the Alnus glutinosa twig with a thick Ee fruiting body, showing two uniseriate rays in longitudinal section. The wood vessels are cut longitudinally, too.

\section{Physics of hair ice}

\subsection{Thermal effects during hair-ice formation}

Insight in the physics of hair ice is found from thermal signatures of hair-ice wood, i.e. the temperature enhancements caused by heat sources associated with the ongoing processes. These include (1) heat generated by fungal metabolism, (2) latent heat of fusion when water freezes in contact with the wood, and (3) heat used or generated by recrystallisation.

Heat generated by these processes diffuses into its environment by radiation, heat conduction, air turbulence, evaporation, and sublimation and therefore exact measurements are difficult to achieve. However, by careful design of the experiments, the main heat loss can be reduced to black-body radiation. For heat sources that change rapidly with time, the temperature changes are damped according to the heat capacity of the wood. On the other hand, under stationary condi- tions the heat power $P$ generated in the wood (at temperature $T_{1}$ ) is equal to the net power that the wood loses to its environment (at temperature $T_{2}$ ). The temperature difference can then be expressed by

$\Delta T=T_{1}-T_{2}=0.25 P \sigma^{-1} A^{-1} T^{-3}$,

where $\sigma=5.673 \times 10^{-8} \mathrm{Wm}^{-2} \mathrm{~K}^{-4}$ is the StefanBoltzmann constant, $A$ the branch surface area, and $T$ the mean absolute temperature of $T_{1}$ and $T_{2}$. The proportionality allows us to express the generated power by temperature differences. Two examples are given below.

\subsubsection{Fungal metabolism}

For the combustion of nutrients by fungal metabolism, we assume a heat of combustion $\mathrm{Qb}=15.6 \mathrm{~kJ} \mathrm{~g}^{-1}$, representative for glucose. A typical branch used in our experiments has a volume of $V=82 \mathrm{~cm}^{3}$ and a surface area of $A=150 \mathrm{~cm}^{2}$ (length $l=26 \mathrm{~cm}$, diameter $d=1.8 \mathrm{~cm}$ ). Such a branch is 


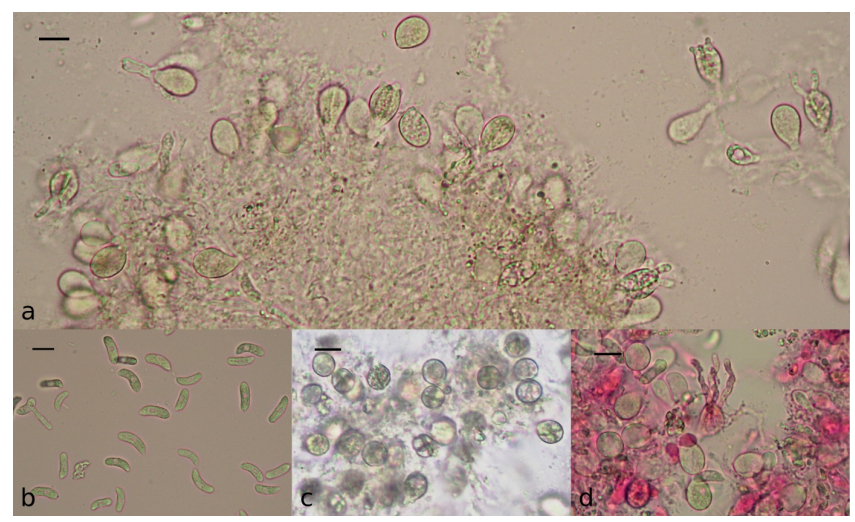

Figure 8. Microscopic characteristics of the Ee fruiting body (scale bar: $10 \mu \mathrm{m}$ ). (a) Ee fruiting body showing longitudinally divided basidia with four sterigmata (squash mount); (b) Ee spores; one is germinating; (c) 4-septate basidia in a cross-sectional view (squash mount); (d) basidium with four long sterigmata (squash mount, coloured by Phloxine B).

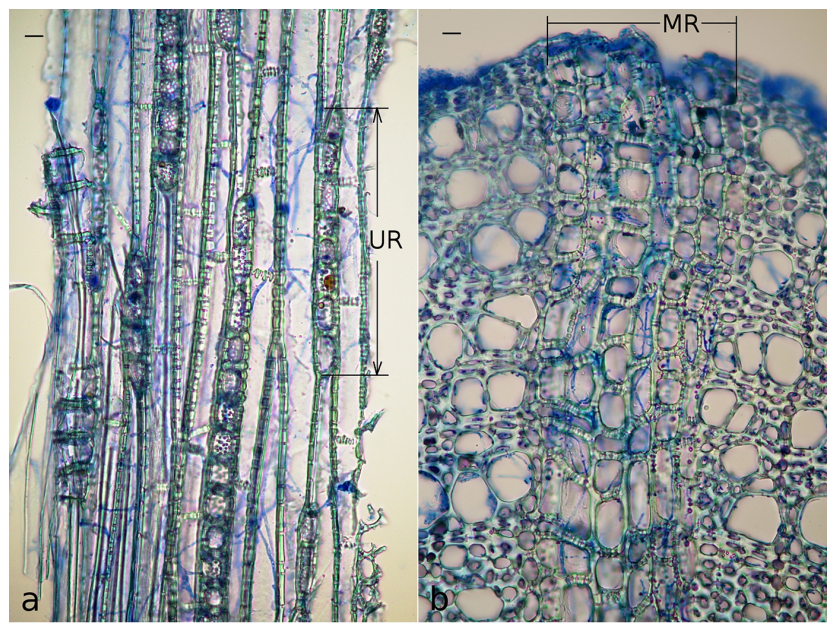

Figure 9. Microscopic view of hair-ice wood showing fungal hyphae coloured by "Cotton Blue" within the wood tissue. The varying thickness of the fungus hyphae was caused by the colouring procedure (scale bar: $10 \mu \mathrm{m}$, UR is an uniseriate ray, MR is a multiseriate ray). Panel (a) shows the tangential section (similar to the look on the surface) of an Alnus glutinosa twig ( $\varnothing 8 \mathrm{~mm})$, that was partly covered by the Ee fruiting body. Several uniseriate rays are shown in the cross section; the wood vessels are cut longitudinally. Panel (b) shows the cross section of a Fagus sylvatica twig $(\varnothing 6 \mathrm{~mm})$ bearing hair ice, that had not yet developed the fungal Ee fruiting body. The wood vessels are shown in cross section; one multiseriate ray is cut longitudinally.

able to produce hair ice over about 1 year. For the active phases of the fungus we assume a duration of $3000 \mathrm{~h}$. Furthermore, assuming $5 \mathrm{~g}$ of nutrients, the rate of combustion is on the order of $1.5 \mathrm{mg} \mathrm{h}^{-1}$. Multiplying this value with $\mathrm{Qb}$ gives $P=7 \mathrm{~mW}$, and for $T=273 \mathrm{~K}$ in Eq. (1) we get $\Delta T=0.1 \mathrm{~K}$, a value that should be measurable under favourable conditions.

\subsubsection{Heat of fusion}

Now, assuming the same branch geometry, latent heat is generated by freezing $1 \mathrm{~g}$ of water per hour. The generated heating power follows from the latent heat of fusion of ice, $L_{\mathrm{f}}=333 \mathrm{~J} \mathrm{~g}^{-1}$ at $T=273 \mathrm{~K}$, as $P=92 \mathrm{~mW}$; inserting this value in Eq. (1) gives $\Delta T=1.3 \mathrm{~K}$. This temperature difference should be easy to measure. Note that it is proportional to the freezing rate.

\subsubsection{Measurement setup}

Branches of beechwood with hair ice were collected in a forest in Moosseedorf, Switzerland. The samples were thoroughly wetted in rainwater. Then they were arranged on a plastic socket put on wet snow to stabilise temperature and to keep the humidity at saturation to avoid evaporation and sublimation. The entire stack was put in a plastic tub that was covered and further insulated with a towel to reduce vapour fluxes and heat conduction inside the tub. The tub was put in a garden hut from mid January to early March 2011, and again in January 2012. Hair ice formed on wood samples during cool nights. From time to time wetting was repeated. With this setup we realised conditions for precise temperature measurements and we therefore approached the assumption that the net heat flux can be represented by Eq. (1). For temperature measurements we used Pt-100 sensors (length $10 \mathrm{~mm}$, diameter $2.6 \mathrm{~mm}$ ). After calibration with an ice-water mixture at $0.00^{\circ} \mathrm{C}$, the sensors were inserted into the wood with the cylinder axis along the radial wood rays (Fig. 10). Temperatures were registered once per second to monitor changes with sufficient time resolution. The effective temperature of the environment was a mean of $T_{0}=273.15 \mathrm{~K}$ of the underlying wet snow and of the tub walls cooled from outside. To represent this value of $T_{2}$ we either used the air temperature inside the tub or the temperature of a dry, passive tracer (hazel wood in 2011) close to the wetted wood samples.

\subsubsection{Experiment of 18-20 January 2011}

First measurements were taken in January 2011. During the first night, $18-19$ January, the temperature stayed above $0{ }^{\circ} \mathrm{C}$ (Mätzler et al., 2013). The time-averaged temperature of the hair-ice branches was $1.213^{\circ} \mathrm{C}$, whereas the value of the passive tracer was $1.203^{\circ} \mathrm{C}$. The difference of $0.010^{\circ} \mathrm{C}$ is very small, similar to the measurement uncertainty.

First hair-ice growth was monitored from 19 to 20 January 2011 with temperature variations shown in Fig. 11. Before midnight all temperatures decreased linearly with time, including the passive tracer. At midnight, sudden increases occurred for all hair-ice branches, indicating ice nucleation and the start of latent-heat release by hair-ice growth. The start 


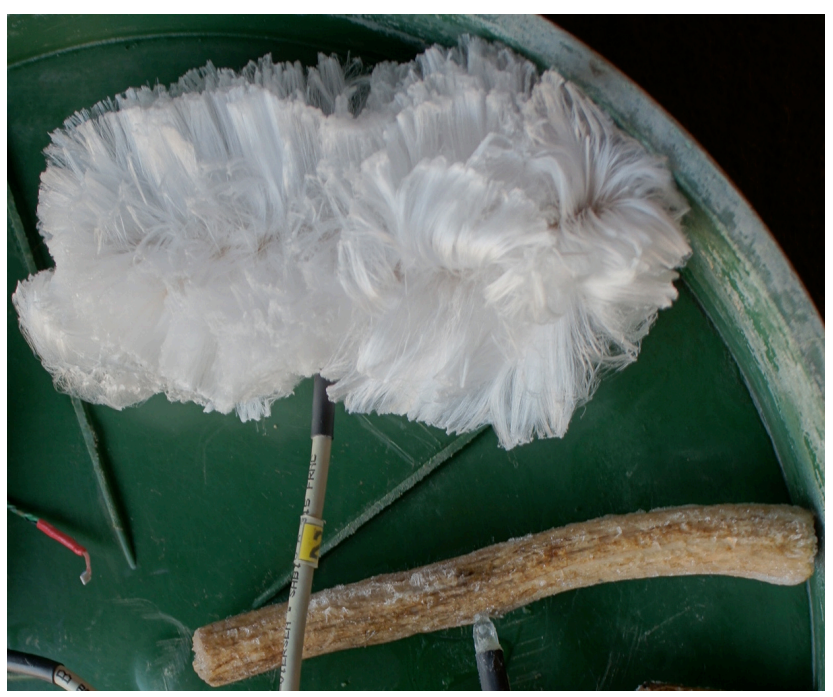

Figure 10. Situation in the morning of 15 January 2012: heattreated piece ( 1 , bottom right), piece (2, top) with abundant hair ice, air temperature sensor (3, bottom left) with red insulation.

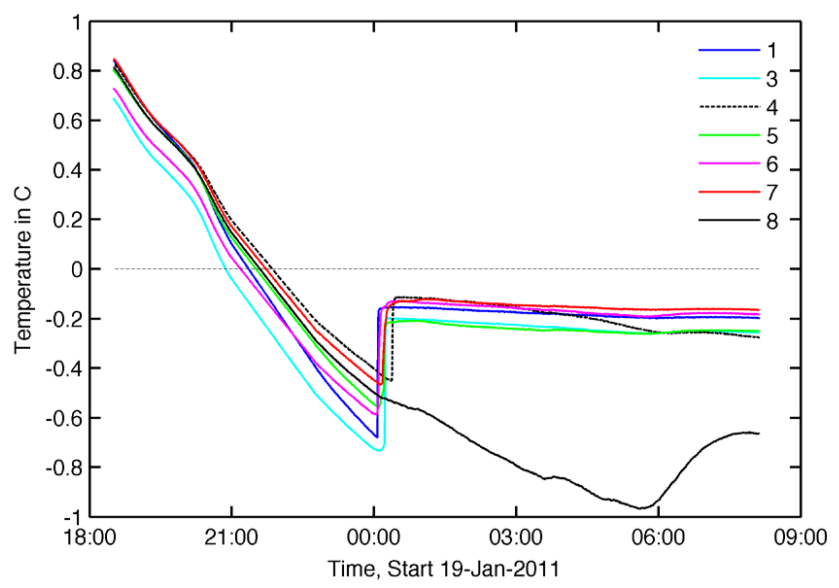

Figure 11. Temperature variation during the first experiment: beechwood samples $(1,3,4,5,6$, and 7) with growing hair ice, and dry hazel wood (8) as a passive tracer of ambient temperature.

is almost simultaneous in all branches, with slightly different nucleation temperature $\left(-0.4\right.$ to $\left.-0.7^{\circ} \mathrm{C}\right)$. Ice grew until the end of the measurement period the following morning. During this period, the temperature of the hair-ice branches remained nearly constant near $-0.2^{\circ} \mathrm{C}$. On the other hand, the passive tracer (8), representing $T_{2}$, continued to cool to $-1{ }^{\circ} \mathrm{C}$ until 05:30 LT without any jumps. Further experiments confirmed these results. The simultaneity of temperature jumps for different hair-ice woods was observed again, but exceptions occurred as well.

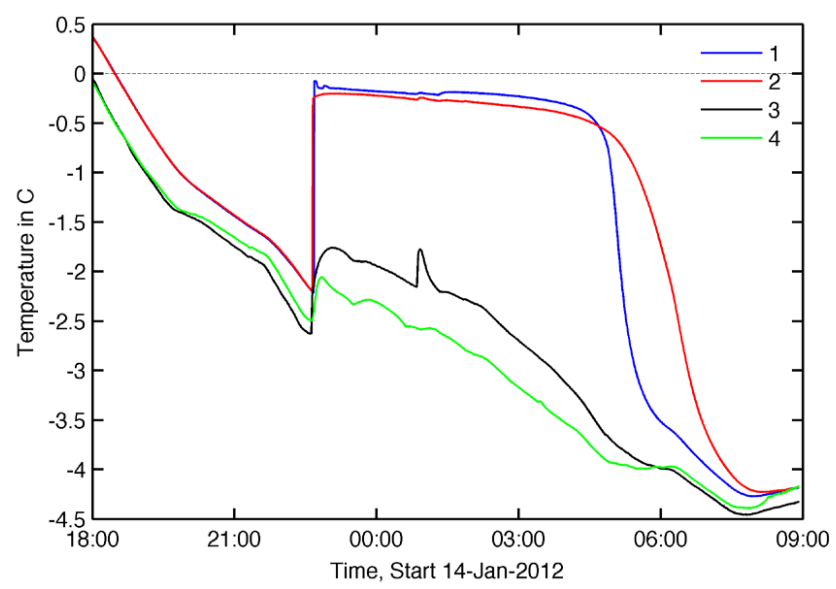

Figure 12. Temperature variation during the second experiment: heat-treated piece (1), untreated piece (2) with hair ice, air temperature close to wood samples (3), and further away (4).

\subsubsection{Experiments of 13-15 January 2012}

In the second year we tried to find out if the fungus activity is a prerequisite of the observed temperature jumps, in other words, if the jumps are signatures for hair-ice formation. We selected a beechwood sample with abundant hairice growth. After wetting it and cutting it in half, both pieces still showed abundant hair-ice growth during the night from 13 to 14 January 2012, with jumps similar to Fig. 11. Then one piece (1) was held in hot water for 5 min to kill the fungus. Both pieces were exposed to the cold again during the following night. As shown in Fig. 10, the untreated sample (2) produced dense hair ice again, but no hair ice was found on the heat-treated sample (1); instead, a thin ice crust covered this wood. The temperature variations are presented in Fig. 12. All sensors started slightly above $0^{\circ} \mathrm{C}$, and all values were near $-4.3^{\circ} \mathrm{C}$ at 09:00 LT the following morning. Due to colder weather, the cooling was faster and reached lower values than in Fig. 11. Both wood samples - with and without hair ice - showed similar and almost simultaneous increases, indicating the onset of freezing at 22:35 LT. Air temperatures at the centre (3) and edge (4) of the container indicate forced cooling with minor modulations.

\subsection{Discussion}

Before the onset of freezing, the temperature of hair-ice branches cannot be distinguished from the environmental temperature. The small difference $\left(0.01^{\circ} \mathrm{C}\right)$ found during the first night in 2011 is representative of the measurement error. This means that heating by fungal metabolism is much more marginal than estimated in Sect. 3.1.1. In other words, the combustion rate of nutrients in our test sample is clearly less than $1 \mathrm{mg} / \mathrm{h}$.

Before freezing begins, the wood temperatures, shown in Fig. 11 and 12, decrease to supercooled conditions below 
$0{ }^{\circ} \mathrm{C}$. A sudden increase marks the onset of freezing by the release of latent heat. The onset in one branch triggers the onset in nearby branches usually within a short time. Ice nucleation appears as an explosive event distributing microscopic ice particles. The temperature increase is similar for samples with hair-ice formation and for samples with killed fungus.

During the phase of ice growth, the wood temperature $\left(-0.1\right.$ to $\left.-0.4{ }^{\circ} \mathrm{C}\right)$ is nearly constant. In addition to the data of Figs. 11 and 12, this range was found in all other measurements that we made (Mätzler et al., 2013). These values are signatures of premelting and thus of ice segregation. The stabilisation is based on the heat of fusion. With falling ambient temperature the freezing rate increases and thus the transfer of latent heat to the wood increases, too. The associated temperature increase compensates for the decrease of the ambient temperature, keeping the branches close to melting point. The stabilisation acts as long as there is sufficient liquid water in the wood rays. The continued freezing dehydrates the branch. When the liquid supply is exhausted, ice production comes to an end, the heat production stops, and the wood temperature converges to the ambient one. This transition is shown near the end in Fig. 12.

The temperature difference between the pieces with and without hair-ice production is small, indicating that the freezing rates are similar. The result means that the fungus activity hardly plays a role for the rate of ice formation. This finding may appear as a surprise when looking at the difference between the branches $(1,2)$ of Fig. 10. But, note that hair ice is extremely fine, its density being extremely small. On the other hand the ice crust on the heat-treated piece (1) mainly consists of bulk ice. To show that its mass is indeed similar to the hair-ice mass, we compare two situations with the same ice volume, one consisting of $N$ hairs per branch surface area, the other one consisting of an ice crust covering the branch surface with a constant thickness $d$. If we denote the hair diameter by $d_{\mathrm{h}}$ and the hair length by $l_{\mathrm{h}}$, it is easy to show

$d=\frac{\pi}{4} N l_{\mathrm{h}} d_{\mathrm{h}}^{2}$.

To get an estimate of $d$ we need the parameters on the right-hand side of Eq. (2). From Fig. 3 and similar observations we find: $d_{\mathrm{h}} \approx 0.014 \mathrm{~mm}, N \approx 20 \mathrm{~mm}^{-2}$, and for the hair length we choose $l_{\mathrm{h}}=50 \mathrm{~mm}$ to get $d=0.15 \mathrm{~mm}$ for the crust thickness. The comparison is consistent with the two branches of Fig. 10.

With regard to Fig. 12, minor differences between Curves (1) and (2) can be noted. Firstly, after freeze onset, Curve (1) shows small oscillations, possibly due to recrystallisation. On the other hand, the temperature variation of Curve (2) is very smooth. Secondly, towards the end, when the strongest cooling occurs, the temperature decrease is slower for Curve (2) with hair ice than in Curve (1) due to thermal insulation by the ice wool.
The similarity of the temperature and thus of the rate of ice growth means that ice segregation is the common mechanism for ice production on the wood surface. The role of the fungus is in shaping the ice as hairs and to prevent it from recrystallisation. This is the main result from the physics of hair ice. Furthermore it indicates that temperature and pressure enhancements associated with fungal metabolism in hair-ice wood (Wagner and Mätzler, 2009) do not appear to be noticeable.

\section{Chemistry of melted hair ice}

\subsection{Organic carbon}

First investigations of non-filtrated and filtrated meltwater samples from hair ice, by means of a total organic carbon analyser (TOC-VCPH, Shimadzu, Japan), show similar and significant amounts of organic carbon $\left(>200 \mathrm{mg} \mathrm{L}^{-1}\right)$ as well as small amounts of (total) nitrogen (>10 $\left.\mathrm{mg} \mathrm{L}^{-1}\right)$. Ion chromatography revealed that the main part $(70 \%)$ of nitrogen consists of ammonium ions. We conclude that melting of hair ice provides us with a real organic carbon solution, mostly free of wood and aerosol particles.

\subsection{Mass spectrometry}

For the elucidation of the unknown components we applied mass spectrometry (MS) aiming at a complete spectrum of organics with regard to molecular size and polarity. Representative screening was achieved by various ionisation techniques in combination with appropriate separation techniques. First, we performed gas chromatography, coupled with electron-impact mass spectrometry (GCEIMS) of filtrated aqueous solutions according to Turska et al. (1997), followed by the more sensitive headspaceGC-EIMS (Seto, 1994, Snow and Slack, 2002). For small carboxylic acids (known as e.g., plant exudates) and peptides/proteins (possible degradation products and/or antifreeze proteins), we used capillary electrophoresis and electrospray Fourier-transform ion cyclotron resonance mass spectrometry (ESI-FTICR-MS, Marshall et al., 1998). None of these methods yielded any significant peak.

In the second step, we applied our most sensitive mass spectrometer equipped with an electrospray source coupled to ultra performance liquid chromatography (UPLC-ESIMS, Swartz, 2005; Guillarme et al., 2010), resulting in first (non-resolved) chromatograms. The electrospray full-scan spectra in positive and negative ionization mode and different retention times are highly complex - ranging over the whole mass range, but similar among themselves. Such spectra-Gaussian in shape with emerging odd-numbered peaks look similar to fulvic/humic acids in dissolved organic matter (DOM) of terrestrial/marine water, soil/sediments, peat bog, kerogen, and eventually crude oil (Kujawinski, 2002; Sleighter and Hatcher, 2007; Hertkorn et al., 2008). 


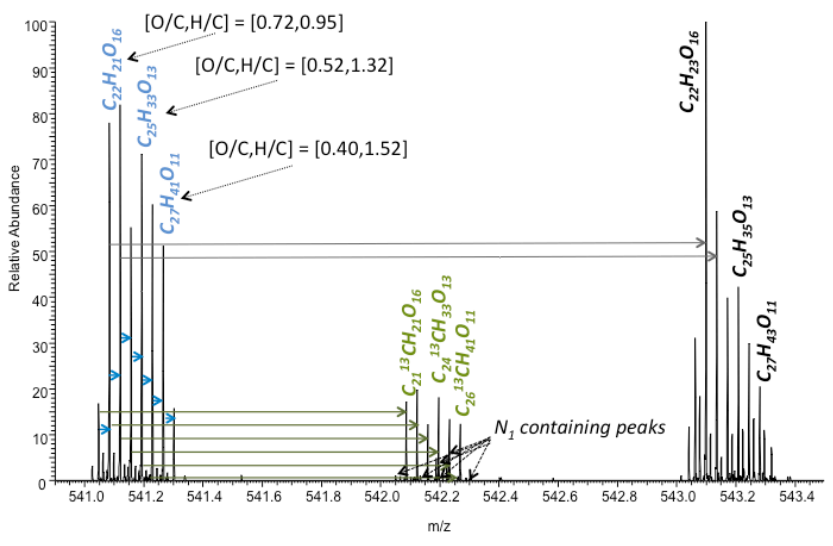

Figure 13. Detail of a high-resolution mass spectrum of melted hair ice.

Therefore, in the third step, we simultaneously desalted and concentrated hair-ice samples by solid-phase extraction (SPE). The methanolic eluates, mixed with $20 \%$ water for better ionisation yield, were introduced again by flow injection in the ultrahigh-resolving ESI-FTICR-MS. In contrast to our former investigation, we arranged the measuring conditions towards complex samples (averaging seven spectra of 50 transients each) to improve the statistics. The high-resolution spectrum in the mass range 200-1000 Da [1 Dalton $(\mathrm{Da})=1.660539 \times 10^{-27} \mathrm{~kg}$, corresponding to $1 / 12$ of the mass of a C-12 atom] show a bimodal distribution (maxima at 500 and 610 Da, not shown). The detailed evaluation of these spectra revealed the typical presence of molecular families containing ions that differ from each other in the number of $\mathrm{CH}_{2}$ groups, the degree of saturation (grey arrows in Fig. 13), and the functional group substitution (blue arrows in Fig. 13), with a significantly higher intensity of the odd-numbered masses (description of such spectra in Leinweber et al., 2009). The reason for the latter phenomenon is the mass spectrometric nitrogen rule: under electrospray conditions the ionisation is by proton transfer to [M$\mathrm{H}]^{-}$or $[\mathrm{M}+\mathrm{H}]^{+}$ions, therefore nitrogen-free organics like $\mathrm{CHO}$ and CHOS compounds are odd-numbered, while organics with one (or three or five) nitrogen atom(s) are evennumbered.

In Fig. 13, ions with the mass space of $0.0364 \mathrm{Da}$ (blue arrows) were derived from the mass difference between $\mathrm{CH}_{4}$ and $\mathrm{O}$, representing the most important formal functional group substitution, giving the typical clusters within a nominal mass. Furthermore, expanded sections of successive, randomly selected nominal masses show that every single (intensive) odd-numbered mass peak has a corresponding lower abundant even-numbered mass peak higher in one $m / z-$ the exact mass space of $1.0034 \mathrm{Da}$ is thereby attributed as its ${ }^{13} \mathrm{C}$ isotopic peak (olive-coloured arrows). Still, the mostly onenitrogen-containing peaks in hair ice are less intense. This result shows the same qualitative tendency as our first organic

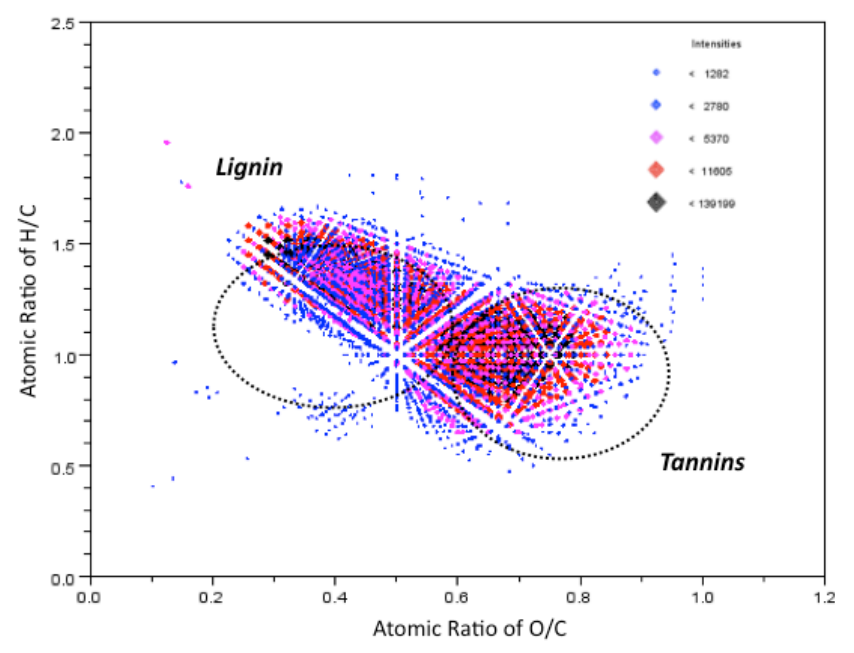

Figure 14. Van Krevelen plot of the $\mathrm{CHO}$ compounds of hair ice (for peak intensities $>600$ counts), with ellipses indicating typical ranges of selected biopolymer components, adapted from Sleighter and Hatcher (2007).

analyses in terms of the organic nitrogen to organic carbon ratio of only approximately $0.014: 1$ - but with the consideration that complex ESI spectra are never quantitative because of the quench effects of easily to poorly ionising substances.

We developed a post-processing to formula assignment of all compounds based on Scilab routines. The resulting mass lists are transformed to Excel tables for sorting and/or preparation of graphical figures describing the characteristics of DOM. The van Krevelen diagram $-\mathrm{H} / \mathrm{C}$ versus $\mathrm{O} / \mathrm{C}$ for all detected compounds - is mostly used to classify the compounds in terms of polarity and aromaticity. Furthermore, Sleighter and Hatcher (2007) and Hockaday et al. (2007) published ranges of biogeochemically important compound classes in such plots. The [O / C, H / C] values found for melted hair ice, which range between [0.40$0.72,1.52-0.95]$, correspond to Sleighter's lignin and tannin ranges, indicated by ellipses in the van Krevelen plot of hair ice and presented in Fig. 14.

\subsection{Discussion}

Mass spectrometry has shown that hair-ice water contains fragments of lignin and tannin. Lignin is a main component (20 to $30 \%$ of dry mass) of wood, stabilising the cells against compression. In contrast to cellulose, it is more difficult to decompose. Lignin is indigestible by animal enzymes; only some fungi (causing white rot) and bacteria are able to secrete lignase and thus biodegrade the polymer. Lignin is an irregular biopolymer with molecular mass in excess of $10000 \mathrm{Da}$, consisting of various types of substructure, that are repeated in a haphazard manner. Tannins are similarly irregular, with molecular weights between 500 and $3000 \mathrm{Da}$ and up to $20000 \mathrm{Da}$ (proanthocyanidins). Lignin and tannin 
consist of hydrophobic skeletal structures with numerous polar functional groups. The hydrophobic lignin/tannin macromolecules may act as crystallisation nuclei.

The lignin and tannin classification was obtained by atomic ratios, shown in Fig. 14. By the application of electrospray, the most gentle mass spectrometric ionisation technique, covalent bonds stay intact whereas the weaker ones (van der Waals bonds and electrostatic bonds) are destroyed. Consequently, molecules in the mass range between 200 and 800 Da result, in general, as fulvic acids do. This means that we are unable to distinguish between the original lignin/tannin macromolecules and their (partial) degradation products.

We also detected sulphur- and nitrogen-containing compounds, but with very small intensities in contrast to the $\mathrm{CHO}$ peaks and in accordance with our TOC and TN measurements. We assume that we detected marginal leftovers from the total degradation of more easily degradable (and nutritious) wood compounds, like proteins, which had already begun the process of mineralisation. This would explain the significant ammonium concentration in melted hair ice.

\section{Conclusions}

Our investigations shed light on the mystery of hair ice that can grow on certain branches of dead wood. The formation is related to a winter-active fungus. Comparatively dense mycelium was observed in the superficial wood cells of hairice-bearing sections of the investigated branches. If the fungus activity is stopped, either by a fungicide or by hot water, the production of hair ice ceases as well.

Hair-ice shape and direction are influenced by the geometry at the mouth of the wood rays where the hairs are formed when the water is freezing. The extreme ratio of hair diameter to hair length with an order of $1: 10000$ is most surprising. In spite of the fact that surface tension tries to reduce this ratio, the shape is maintained over many hours, and sometimes several days at temperatures close to melting point. A recrystallisation inhibitor must be responsible for stabilising the hairs. It may be contained in the thread-forming fibre that appears when hair ice starts to melt, and it could be related to lignin, the main organic component that we found.

With respect to the origin of water, hair ice is a basicryogen, meaning that the ice originates from water in a porous substrate, in our case, the wood. Inside the substrate, melting point is lowered by intermolecular forces in the interface between ice and the substrate, called premelting. When the external temperature is sufficiently low, water freezes on suitable nuclei on the substrate surface and transfers latent heat of fusion to the substrate. Once ice nuclei have formed, ice segregation starts to extract additional water from the substrate, leading to the growth of ice and to the dehydration of the substrate. We found that this effect occurs under the same conditions with similar freezing rates in wood with and without hair-ice production.

The fungus provides decomposed lignin and tannin as organic materials. The notion that they may act as recrystallisation inhibitors is indicated by properties of lignosulfonate (waste of cellulose production) found in Sandermann and Dehn (1951), namely that it delays the hardening of cement.

The fungus activity plays a minor role with regard to the rate and amount of ice formation. Hair-ice branches with active and with killed fungus undergo similar temperature curves, indicating that the freezing rates are very similar and that fungal metabolism is too weak to cause a measurable temperature enhancement. The difference must be in shaping the ice. Whereas the untreated branches produce hair ice, the heat-treated ones produce crusty ice sticking to the wood surface. Although the fungus effect is still a mystery, it must be directly related to the hair-ice shape because the suppression of hair-ice growth acts immediately after the fungus activity is stopped.

Our findings not only confirm Wegener's hypothesis that fungal activity plays an important role, but they unravel the mystery about the whitish covering on hair-ice-producing wood, described by Wegener (1918) and Wagner (2005). There is clear evidence to suggest a causal relationship between the fungus, Exidiopsis effusa, and the growth of hair ice. This fungus is known to cause white rot. Indeed, the brightness of hair-ice wood increases with age, and its dry density decreases more and more, indicating wood decomposition. The chemical analysis confirms and specifies the degradation. Explaining further details of the connection between the fungus and hair ice will be tasks for future research.

Author contributions. For several years, C. Mätzer has been working (in collaboration with Gerhart Wagner) on hair ice, its observation in nature, reproduction, and the test of a fungus hypothesis. In the presented paper he is mainly responsible for the physical measurements and interpretations, described in Sect. 3. G. Preuss investigated the fungi and the wood samples by microscopic techniques, described in Sect. 2.2, leading to the identification of Ee. D. Hofmann performed and interpreted the chemical analyses presented in Sect. 4. The paper is a strong collaboration of scientists from different fields with one object of collective discussion.

Acknowledgements. We thank Gerhart Wagner for contributing Sect. 2.1 including Fig. 5. We regret his wish not to act as a co-author. We thank the Institute of Applied Physics, University of Bern for support with the temperature measurements. Niklaus Kämpfer and Andreas Hasler first indicated possible relationships between hair ice and ice-segregation processes to us. Bernhard Steffen, JSC, Forschungszentrum Jülich, developed the Scilab-based evaluation program. 
The article processing charges for this open-access publication were covered by a Research

Centre of the Helmholtz Association.

Edited by: J. Kesselmeier

\section{References}

Bavendamm, W.: Erkennen, Nachweis und Kultur der holzverfärbenden und holzzersetzenden Pilze, in: Handbuch der biologischen Arbeitsmethoden, Herausgeber: Abderhalden, E., Abt. XII, 27-1134, Urban \& Schwarzenberg, Berlin und Wien, 1936.

Dash J. G.: Thermomolecular Pressure in Surface Melting: Motivation for Frost Heave, Science, 246, 1591-1593, 1989.

Dash, J. G., Fu, H., and Wettlaufer, J. S.: The premelting of ice and its environmental consequences, Rep. Prog. Phys., 58, 115-167, 1995.

Dash, J. G., Rempel, A. W., and Wettlaufer, J. S.: The physics of premelted ice and its geophysical consequences, Rev. Mod. Phys., 78, 695-741, 2006.

Gminder, A.: Handbuch für Pilzsammler, Frankh-Kosmos, Stuttgart, 2008.

Griffith, M. and Yaish, M .W. F.: Antifreeze proteins in overwintering plants: a tale of two activities, Trends Plant Sci., 9, 400-405, 2004.

Guillarme, D., Ruta, J., Rudaz, S., and Veuthey, J. L.: New trends in fast and high-resolution liquid chromatography: a critical comparison of existing approaches, Anal. Bioanal. Chem., 397, 1069-1082, 2010.

Haller, B. and Probst, W.: Botanische Exkursionen im Winterhalbjahr, Gustav Fischer, Stuttgart, New York, 1983.

Heilmann-Clausen J. and Christensen, M.: Fungal diversity on decaying beech logs - implications for sustainable forestry, Biodivers. Conserv., 12, 953-973, 2003.

Hertkorn, N., Frommberger, M., Witt, M., Koch, B. P., SchmittKopplin, P., and Perdue, E. M.: Natural Organic Matter and the Event Horizon of Mass Spectrometry, Anal. Chem., 80, 89088919, 2008.

Hockaday, W. C., Grannas, A. M., Kim, S., and Hatcher, P. G.: The transformation and mobility of charcoal in a fire-impacted watershed, Geochim. Cosmochim Ac., 71, 3432-3445, 2007.

Jülich, W.: Basidiomyceten, in: Kleine Kryptogamenflora, Herausgeber: Gams, H., Band IIb, 1. Teil, Gustav Fischer, Stuttgart, New York, 1984.

Knoll, F.: Untersuchungen über den Bau und die Funktion der Zystide und verwandter Organe, Jahrbuch wiss. Bot., 50, 453-501, 1912.

Krieglsteiner, G. J. (Hrsg.): Die Großpilze Baden-Württembergs, Band 1: Allgemeiner Teil: Ständerpilze: Gallert-, Rinden-, Stachel- und Porenpilze, Ulmer, Stuttgart, 2000.

Kujawinski, E. B.: Electrospray ionization Fourier transform ion cyclotron resonance mass spectrometry (ESI FT-ICR MS): characterization of complex environmental mixtures, Environ. Forensics, 3, 207-216, 2002.

Laux, H. E.: Der große Kosmos Pilzführer, Frankh-Kosmos Verlags-GmbH \& Co. KG, Stuttgart, 2010.

Leinweber, P., Jandl, G., Eckhardt, K. U., Schulten, H. R., Schlichting, A., and Hofmann, D.: Analytical pyrolysis and soft- ionization mass spectrometry, in: Biophysico-chemical processes involving natural nonliving organic matter in environmental systems, Herausgeber: Senesi, J., Xing, B., and Huang, P. M., 1st Edn., Wiley, Hoboken, 539-588, 2009.

Lenggenhager, K.: Zur Frage der Haareis-Bildung, Arch. Meteor. Geophy. B., 36, 371-379, 1986.

Marshall, A. G., Hendrickson, C. L., and Jackson, G. S.: Fourier Transform Ion Cyclotron Resonance Mass Spectrometry: A Primer, Mass Spectrom. Rev., 17, 1-35, 1998.

Mätzler, C., Wagner, G., Preuss, G., and Hofmann, D.: Enlightening the Mystery of Hair Ice, IAP Research Report 2013-01-MW, Institute of Applied Physics, University of Bern, Bern, 2013.

Moser, M.: Ascomyceten, in: Kleine Kryptogamenflora, Herausgeber: Gams, H., Band IIa, Gustav Fischer Stuttgart, 1963.

Mühleisen, R. and Lämmle, A.: Neue Untersuchungen von Kammeis (Haareis), Meteorol. Rundsch., 28, 55-60, 1975.

Ozawa, H.: Thermodynamics of frost heaving: A thermodynamic proposition for dynamic phenomena, Phys. Rev. E, 56, 28112816, 1997.

Ozawa, H. and Kinosita, S.: Segregated ice growth on a microporous filter, J. Colloid Interf. Sci., 132, 113-124, 1989.

Petersen, J. H. and Læssøe, T.: MycoKeyTM - the mycological information site, www.mycokey.com (last access: 17 January 2013), 2003.

Rempel, A. W., Wettlaufer, J. S., and Worster M. G.: Premelting dynamics in a continuum model of frost heave, J. Fluid Mech., 498, 227-244, 2004

Richter, H. G. and Dallwitz, M. J.: Commercial timbers: descriptions, illustrations, identification, and information retrieval, in English, French, German, and Spanish, Version May 04, www. delta-intkey.com/wood/ (last access: 17 January 2013), 2000.

Riggenbach , A: Untersuchungen über den Eschenpilz, Promotionsarbeit Nr. 2561, ETH Zürich, Phytopatologische Zeitschrift, Band 27, Heft 1, 1-40, Verlag Paul Parey, Berlin, Hamburg, 1956.

Robert, V., Stegehuis, G., and Stalpers, J.: The MycoBank engine and related databases www.mycobank.org (last access: 17 January 2013), 2005.

Rothmaler, W. (Begr.): Exkursionsflora von Deutschland, Band 1: Niedere Pflanzen, 3 Auflage, Elsevier, München, 1994.

Sandermann, W. and Dehn, U.: Einfluß chemischer Faktoren auf die Festigkeitseigenschaften zementgebundener Holzwolleplatten, Holz Roh. Werkst., 9, 97-101, 1951.

Schoch, W., Heller, I., Schweingruber, F. H., and Kienast, F.: Wood anatomy of central European Species, www.woodanatomy.ch (last access: 17 January 2013), 2004.

Schweingruber, F. H.: Anatomie europäischer Hölzer, Paul Haupt, Bern and Stuttgart, 1990.

Seto, Y.: Determination of volatile substances in biological samples by head space gas-chromatography, J. Chromatogr., 674, 25-62, 1994.

Sleighter, R. L. and Hatcher, P. G.: The application of electrospray ionization coupled to ultrahigh resolution mass spectrometry for the molecular characterization of natural organic matter, J. Mass Spectrom., 42, 559-574, 2007.

Snow, N. H. and Slack, G. C.: Head-space analysis in modern gas chromatography, TRAC-Trends, Anal. Chem., 21, 608-617, 2002. 
Sprecher, E.: Über die Guttation bei Pilzen, Planta, 53, 565-574, 1959.

Swartz, M. E.: UPLC (TM): An introduction and review, J. Liq. Chromatogr. R. T., 28, 1253-1263, 2005.

Thielke, C.: Membranaggregate und Filamente in den Zystiden von Volvariella bombacina, Zeitschr. Mykologie, 49, 257-264, 1983.

Turska, M., Wolska, L., Zygmunt, B., and Namiesnik, J.: Direct injection of aqueous samples into gas chromatographic columns, Chemia Analityczna, 42, 787-797, 1997.

Vignes, M. and Dijkema, K. M.: A Model for the Freezing of Water in a Dispersed Medium, J. Colloid Interf. Sci., 49, 165-172, 1974.
Wagner, G.: Haareis - eine seltene winterliche Naturerscheinung, Schweiz Zeitschrift für Pilzkunde, November 2005, 269-271, 2005.

Wagner, G. and Mätzler, C.: Haareis - Ein seltenes biophysikalisches Phänomen im Winter, Naturwissenschaftliche Rundschau, 62, 117-123, 2009.

Wegener, A.: Haareis auf morschem Holz, Die Naturwissenschaften, 6, 598-601, 1918. 